\title{
Macrophage migration inhibitory factor gene polymorphisms as exacerbating factors of apical periodontitis
}

\author{
Andrea Freer-Rojas $5^{1, A, B, D}$, Luis Carlos Martínez-Garibay ${ }^{1, A, B, D}$, Fernando Torres-Méndez ${ }^{1, A, C}$, Claudia Edith Dávila-Pérez ${ }^{1, A, C}$, \\ Gabriel Alejandro Martínez-Castañón ${ }^{2, E, F}$, Nuria Patiño-Marín ${ }^{2, E, F}$, Jorge Alejandro Alegría-Torres ${ }^{3,4, A, C-F}$ \\ ${ }^{1}$ Department of Endodontics, Dental School, Autonomous University of San Luis Potosí, Mexico \\ ${ }^{2}$ Clinical Research Laboratory, Program of Doctorate in Dental Sciences, Autonomous University of San Luis Potosí, Mexico \\ ${ }^{3}$ Department of Pharmacy, University of Guanajuato, Mexico \\ ${ }^{4}$ Molecular Nutrition Research Laboratory, LIMON, University of Central Mexico UCEM, San Luis Potosí, Mexico \\ A - research concept and design; B - collection and/or assembly of data; $\mathrm{C}$ - data analysis and interpretation; \\ $D$ - writing the article; $E$ - critical revision of the article; $F$ - final approval of the article
}

Address for correspondence

Jorge Alegría-Torres

E-mail: ja.alegriatorres@ugto.mx

Funding sources

None declared

Conflict of interest

None declared

Received on June 27, 2018

Reviewed on July 30, 2018

Accepted on April 29, 2020

Published online on May 19, 2020

Cite as

Freer-Rojas A, Martínez-Garibay LC, Torres-Méndez F, et al.

Macrophage migration inhibitory factor gene polymorphisms as exacerbating factors of apical periodontitis. Adv Clin Exp Med. 2020;29(5):597-602. doi:10.17219/acem/121508

DOI

10.17219/acem/121508

Copyright

Copyright by Author(s)

This is an article distributed under the terms of the

Creative Commons Attribution 3.0 Unported (CC BY 3.0)

(https://creativecommons.org/licenses/by/3.0/)

\section{Abstract}

Background. Two polymorphisms in the macrophage migration inhibitory factor (MIF) gene have been associated with inflammatory diseases (-794 (ATT5-8 and $-173 \mathrm{G}>$ C); however, so far there are no reports of studies related to oral health.

Objectives. To genotype the -794 CATT5-8 and -173G>C MIF polymorphisms in Mexican patients with apical periodontitis as a genetic risk of exacerbation.

Material and methods. The study involved 120 patients with apical periodontitis: 60 with a diagnosis of acute apical periodontitis (Group A) and 60 without previous episodes of exacerbation (Group B). Allelic discrimination was performed from peripheral blood DNA; the repeat polymorphism -794 CATT5-8 was genotyped with sequencing, while the $-173 \mathrm{G}>$ C polymorphism was determined using real-time polymerase chain reaction (RT-PCR) using TaqMan probes. The associations between MIF polymorphisms, haplotypes and the risk of exacerbated apical periodontitis were assessed.

Results. The allele CATT7 was associated with the risk of a stage of acute inflammation (OR = 4.13; $95 \% \mathrm{Cl}=1.82-9.63 ; p=<0.001)$. Regarding the $-173 \mathrm{G}>$ C polymorphism, a process of inflammation exacerbation was only associated with the $C($ genotype $(O R=4.1 ; 95 \% \mathrm{Cl}=1.02-20.84 ; p=0.045)$. The analysis of the haplotype showed that the combination CATT7/C increases the risk of exacerbation of apical periodontitis $(O R=3.57 ; 95 \% \mathrm{Cl}=1.038-13.300 ; p=0.021)$.

Conclusions. The polymorphisms -794 CATT5-8 and -173G > C MIF seem to significantly influence the development of a state of exacerbated inflammation in patients with apical periodontitis.

Key words: apical periodontitis, genetic polymorphisms, macrophage migration inhibitory factor 


\section{Introduction}

Periodontitis is an inflammatory condition which affects areas such as the gingivae, periodontal ligaments and alveolar bones because of viral or bacterial infections. In acute episodes, there is pain because of an increase in hypersensitivity to touch. ${ }^{1}$ According to several studies, the prevalence of periodontitis increases with age and could be a problem in more than $60 \%$ of the world population. ${ }^{2-4}$ When acute inflammation becomes apparent in the tissue, cells of the immune system such as macrophages, lymphocytes and plasma cells are wrapped in collagenous connective tissue as part of the antimicrobial response. As a result, the cytokines block not only the osteoclastic activity but also bone reabsorption, leading to asymptomatic latent or inactive granuloma without visible changes in a radiographic image. ${ }^{1}$

When the balance of the periapical area is broken, bacterial proliferation can be triggered towards the radicular conduct and periapical tissues, with subsequent exacerbation of chronic periodontitis, which manifests itself in the formation of a secondary abscess. ${ }^{5}$ In this process, interleukins such as tumor necrosis factor $\alpha$ (TNF- $\alpha$ ), interleukin 1b (IL-1b), IL-6, and IL-8 intervene as mediators of inflammation. ${ }^{6}$ The macrophage migration inhibitory factor (MIF) is another regulatory cytokine of the innate immune response expressed by macrophages, monocytes, B cells and dendritic cells as well as granulocytes. ${ }^{7,8}$

The MIF is considered an important component in the defense against bacterial infections, since this cytokine promotes the release of pro-inflammatory molecules ${ }^{9,10}$; however, its overexpression could lead to an acute exacerbated response. In fact, MIF has been used as a biomarker of diseases with a relevant inflammatory component. ${ }^{11,12}$

Two polymorphisms located in the promotor region of the MIF gene are associated with inflammatory diseases. First, the short tandem repeat $\mathrm{CATT}_{5-8}$ is a tetranucleotide that is repeated between 5 and 8 times in position -794; increases in the numbers of repetitions produce a corresponding increase in MIF promoter activity. ${ }^{13}$ On the other hand, C-173G, a single nucleotide polymorphism (SNP), acts to enhance the union of the transcription factor AP4 and the subsequent overexpression of MIF. ${ }^{14}$ Both polymorphisms have been studied as factors related to the pathogenesis of sepsis, severe acute respiratory syndrome, asthma, arthritis, glomerulonephritis, and inflammatory bowel disease. ${ }^{12,15}$

However, we have found no scientific reports that associate MIF polymorphisms with acute inflammatory processes in the oral cavity. Therefore, the goal of this study was to evaluate the risk of exacerbation in Mexican patients with a diagnosis of apical periodontitis by analyzing the distribution of alleles, genotypes and haplotypes in 2 groups: patients without previous episodes of exacerbation, and patients with a medical history of exacerbation.

\section{Material and methods}

\section{Characteristics of the study groups}

A cross-sectional study of 120 patients including 46 males (38.3\%) and 74 females (61.7\%) between 18 and 72 years of age diagnosed with apical periodontitis at the endodontic clinic at the University of San Luis Potosí, Mexico, was carried out. Anthropometric data and clinical histories were collected from all patients. The individuals were classified into 2 groups according to clinical assessment.

Group A included 60 patients with pulp necrosis associated with acute apical abscess or phoenix abscess. Symptoms could vary from moderate to severe, including intraoral/extraoral edema, exudate, tumefaction, and pain on palpation or percussion. In severe cases, fever and/or lymphadenopathy could also be observed. When the diagnosis was acute apical abscess, no periapical lesion could be detected radiographically, while for a phoenix abscess, a periapical lesion could be greater than $2 \mathrm{~mm}$.

Group B also included 60 patients with chronic apical periodontitis, but without a previous history of exacerbation. A negative response to a cold thermic test was diagnosed as pulp necrosis. The patients could have mild or no pain on palpation or percussion. Radiographically, a periapical lesion with a diameter wider than $2 \mathrm{~mm}$ needed to be detected.

This project was previously approved by the bioethics committee at the Autonomous University of San Luis Potosí (approval No. CEJ-FE-009-014), and informed consent was obtained from all the participants prior to initiating our study. All the procedures performed were in accordance with the 1964 Helsinki Declaration and its later amendments or comparable ethical standards.

\section{DNA purification}

DNA was isolated from blood obtained by venous puncture and preserved at $-80^{\circ} \mathrm{C}$ in accordance with a previously described protocol. ${ }^{16}$ Briefly, $1 \mathrm{~mL}$ of blood was treated with a pH 7.5 lysis solution (0.3 M sucrose, $10 \mathrm{mM}$ Tris- $\mathrm{HCl} \mathrm{pH}$ 7.5, $5 \mathrm{mM} \mathrm{MgCl}_{2}$, and 1\% Triton X-100). Leukocytes were obtained with centrifugation and washed with the lysis solution. Subsequently, the pellet was suspended in $10 \mathrm{mM}$ Tris- $\mathrm{HCl}$ pH 8 and lysed with $20 \mathrm{mg} / \mathrm{mL}$ laundry detergent. Proteins were precipitated with $5 \mathrm{M} \mathrm{NaCl}$ and the supernatant was treated with cold $96 \%$ ethanol. The DNA was washed with $70 \%$ ethanol and suspended in nuclease-free water. The samples were analyzed with the help of a UV-spectrophotometer at $260 \mathrm{~nm}$ and $280 \mathrm{~nm}$. The ratio of the absorbance at $260 \mathrm{~nm}$ and $280 \mathrm{~nm}$ (A260/280) was used as indicator of purity of DNA; a value between 1.4 and 2 was considered acceptable. The DNA samples were standardized to a final concentration of $30 \mathrm{ng} / \mu \mathrm{L}$ and frozen until use. All the reagents were purchased from Sigma-Aldrich (St. Louis, USA). 


\section{Genotyping}

$\mathrm{CATT}_{5-8}$ repetitions in the position -794 of the MIF gene were identified with sequencing from a polymerase chain reaction (PCR) product obtained using the following oligonucleotides: (F) 5'- TGTCCTCTTCCTGCTATGTC/(R) 5'CACTAATGGTAAACTCGGGG $-3{ }^{\prime} .{ }^{17}$ The final volume of each PCR was $25 \mu \mathrm{L}$ with the following composition: $5 \mu \mathrm{L} 5 \times$ iProof $^{\mathrm{TM}}$ HF Buffer (BioLabs, Cambridge, USA), $120 \mathrm{ng}$ of DNA and $0.125 \mu \mathrm{L}$ of Taq polymerase (1.25 units). For each primer, the final concentrations were $200 \mathrm{nM}$ and $200 \mu \mathrm{M}$ for deoxynucleotide triphosphates (dNTPs) (BioLabs). The amplification conditions were 1 cycle at $95^{\circ} \mathrm{C}$ for $1 \mathrm{~min} ; 35$ cycles at $95^{\circ} \mathrm{C}$ for $30 \mathrm{~s}, 60^{\circ} \mathrm{C}$ for $30 \mathrm{~s}$ and $72^{\circ} \mathrm{C}$ for $30 \mathrm{~s}$; and finally, 1 cycle at $72^{\circ} \mathrm{C}$ for $2 \mathrm{~min}$. All PCR assays were performed in duplicate in a $\mathrm{T} 100^{\mathrm{TM}}$ Thermal Cycler (Bio-Rad Laboratories Inc., Hercules, USA). The amplification products were previously verified in $3 \%$ agarose gel electrophoresis, and the sequencing service was provided by LANBAMA (IPICYT, San Luis Potosí, Mexico).

The MIF -173G>C polymorphism was detected with real-time PCR (RT-PCR) using allele-specific oligonucleotide probes for both wild-type and mutant alleles, labeled with different fluorescent tags. The primers used were as follows: (F) 5'-CCAGCAACCGCCGCTAAG-3'/(R) 5'-TGGCGACTAACATCGGTGA-3', and the probe for the $-173 \mathrm{G}$ allele was [Q705]- ACCGCTCCAACCTGTT-[BHQ2], while the probe for the -173C allele was [Cy5]-CCGCTCCAAGCTGTT-[BHQ2]. The primers and probes were designed by RealTimeDesign software and purchased from BioSearch Technologies Inc. (Petaluma, USA). The qPCR was carried out with $30 \mathrm{ng}$ of genomic DNA. Each sample $(10 \mu \mathrm{L})$ was analyzed in duplicate and contained $5 \mu \mathrm{L}$ of iQTM Multiplex Powermix (Bio-Rad) and $300 \mathrm{nmol}$ of each primer and probe. The PCR cycles were programmed on a CFX96 Touch Realtime PCR detection system (Bio-Rad) and consisted of hotstart incubation $\left(95^{\circ} \mathrm{C}, 3 \mathrm{~min}\right)$ and amplification for 45 cycles $\left(95^{\circ} \mathrm{C}, 15 \mathrm{~s} ; 59^{\circ} \mathrm{C}, 1 \mathrm{~min}\right)$. Genotypes were distinguished by post-read PCR fluorescence of normalized reported values for wild-type and mutant alleles. The genotype of each sample was determined using a multicomponent algorithm, generating 3 allelic clusters: GG, GC and CC genotypes.

\section{Statistical analysis}

Geometric means and standard deviations (SD) were calculated for continuous variables, percentages by gender and frequencies for alleles, genotypes and haplotypes. Comparisons of means between the 2 study groups were analyzed using the Mann-Whitney $U$ test, while differences in the distribution of alleles and genotypes were analyzed using the $\chi^{2}$ test. The Hardy-Weinberg equilibrium for the alleles was measured using the $\chi^{2}$ test, and the linkage disequilibrium (LD) between the loci was calculated using a 2-locus LD calculator.

The association magnitude was quantified with odds ratios (OR) with $95 \%$ confidence intervals (95\% CI) to calculate the risk of exacerbation of apical periodontitis. A binomial logistic regression analysis was used after categorization by alleles, genotypes and haplotypes, considering the clinical diagnosis as a dependent variable with a binary outcome (acute vs chronic apical periodontitis). Results were considered statistically significant when $\mathrm{p}<0.05$. All the analyses were performed with an IBM SPSS v. 19.0 statistic software package (IBM Corp., Armonk, USA).

\section{Results}

A total of 120 patients with diagnoses of apical periodontitis were included in this study, $50 \%$ with a history of at least 1 acute episode (Group A) and the other half with chronic apical periodontitis without exacerbations (Group B). The percentages of women and men were 62.7 and 37.3, respectively; the average age was 36.4 years. With respect to the body mass index (BMI), $43.2 \%$ corresponded to normal weight, $35.2 \%$ to overweight and $21.6 \%$ to obesity. Age, the proportion of women and men and BMI did not differ between the 2 groups when the data was statistically analyzed. These results are summarized in Table 1.

The allelic and genotyping frequencies, as well as the distribution of them between the 2 study groups, are shown in Table 2. In the case of the MIF -794 $\mathrm{CATT}_{5-8}$ polymorphisms, frequencies of $0.23,0.57$ and 0.2 were found for $\mathrm{CATT}_{5}, \mathrm{CATT}_{6}$ and $\mathrm{CATT}_{7}$, respectively; the $\mathrm{CATT}_{8}$

Table 1. Characteristics of the study population

\begin{tabular}{|c|c|c|c|c|}
\hline Variable & $\begin{array}{c}\text { Total } \\
\mathrm{n}=120 \\
\operatorname{mean}(\min -\max )(\%)\end{array}$ & $\begin{array}{c}\text { Group } A\left(A P^{*}\right) \\
n=60 \\
\text { mean }(\min -\max )(\%)\end{array}$ & $\begin{array}{c}\text { Group } B\left(C P^{*}\right) \\
n=60 \\
\text { mean }(\min -\max )(\%)\end{array}$ & $\mathrm{p}$-value \\
\hline Age mean (min-max) & $36.4(12-72)$ & $37.4(18-69)$ & $35.6(12-72)$ & $0.45^{\mathrm{a}}$ \\
\hline Women & 62.7 & 50 & 74 & $0.13^{b}$ \\
\hline Men & 37.3 & 50 & 26 & - \\
\hline BMI, mean (min-max) & $26.7(18.4-46.3)$ & $27.1(18.4-36.6)$ & $26.4(18.4-46.3)$ & $0.33^{\mathrm{a}}$ \\
\hline Normal weight & 43.2 & 37.5 & 48.2 & - \\
\hline Overweight & 35.2 & 41.7 & 29.6 & - \\
\hline Obesity & 21.6 & 20.8 & 22.2 & $0.64^{b}$ \\
\hline
\end{tabular}

aMann-Whitney $U$ test; ${ }^{b} X^{2}$ test; ${ }^{*} A P$ - acute periapical periodontitis; CP - chronic periapical periodontitis; BMI - body mass index. 
Table 2. Allelic and genotypic frequencies of -794 CATT 5-8 $_{-8}$ and G-173C MIF polymorphisms in the study group

\begin{tabular}{|c|c|c|c|c|}
\hline $\begin{array}{c}\text { MIF } \\
\text { polymorphism }\end{array}$ & $\begin{array}{l}\text { Total } \\
\mathrm{n}(\%)\end{array}$ & $\begin{array}{c}\text { Group } A \\
\left(A P^{*}\right) \\
n\end{array}$ & $\begin{array}{c}\text { Group B } \\
\left(C P^{*}\right) \\
n\end{array}$ & $p$-value ${ }^{b}$ \\
\hline \multicolumn{5}{|c|}{-794 CATT $_{5-8}$} \\
\hline \multicolumn{5}{|c|}{ Allele } \\
\hline $\mathrm{CATT}_{5}$ & $55(23)$ & 16 & 39 & 0.001 \\
\hline $\mathrm{CATT}_{6}$ & $136(57)$ & 73 & 63 & \\
\hline $\mathrm{CATT}_{7}$ & $49(20)$ & 31 & 18 & \\
\hline $\mathrm{CATT}_{8}$ & 0 & 0 & 0 & \\
\hline \multicolumn{5}{|c|}{ Genotype } \\
\hline CATT 5/5 & $12(10)$ & 3 & 9 & 0.060 \\
\hline CATT 5/6 & $26(22)$ & 8 & 18 & \\
\hline CATT 5/7 & $5(4)$ & 2 & 3 & \\
\hline CATT 6/6 & $50(42)$ & 30 & 20 & \\
\hline CATT 6/7 & $10(8)$ & 5 & 5 & \\
\hline CATT $7 / 7$ & $17(14)$ & 5 & 12 & \\
\hline \multicolumn{5}{|c|}{ G-173C } \\
\hline \multicolumn{5}{|c|}{ Allele } \\
\hline G & $150(62.5)$ & 68 & 82 & 0.125 \\
\hline$C$ & $90(37.5)$ & 50 & 40 & \\
\hline \multicolumn{5}{|c|}{ Genotype } \\
\hline GG & $43(36)$ & 19 & 24 & 0.122 \\
\hline GC & $64(53)$ & 30 & 34 & \\
\hline$C C$ & $13(11)$ & 10 & 3 & \\
\hline
\end{tabular}

${ }^{b} X^{2}$ test; *AP - acute periapical periodontitis; CP - chronic periapical periodontitis.

allele was not found in any of the participants. Regarding the $-173 G>C$ polymorphism, the frequencies for $G$ and $C$ alleles were 0.625 and 0.375 , respectively, following the Hardy-Weinberg equilibrium $\left(x^{2}=2.28, \mathrm{p}=0.13\right)$. Both $M I F$ polymorphisms were found in linkage disequilibrium $\left(D^{\prime}=0.635, r^{2}=0.179, X^{2}=17.72\right)$. When the distribution of alleles and genotypes of $-794 \mathrm{CATT}_{5-8}$ and $-173 \mathrm{G}>\mathrm{C}$ variants were analyzed between the 2 study groups, we found that only the CATT polymorphism had a different statistically significant distribution between the groups $(\mathrm{p}=0.001)$.

Odds ratios were measured for MIF polymorphisms according to the classification of apical periodontitis (acute vs chronic). As shown in Table 3, an association was established in individuals carrying the alleles -794 $\mathrm{CATT}_{6}(\mathrm{OR}=2.8 ; 95 \% \mathrm{CI}=1.44-5.62 ; \mathrm{p}=0.002)$ and $\mathrm{CATT}_{7}(\mathrm{OR}=4.13 ; 95 \% \mathrm{CI}=1.82-9.63 ; \mathrm{p}<0.001)$, while no association with the $-173 \mathrm{C}$ allele was found. The analysis by genotype showed that the CATT risk alleles are associated with acute episodes of apical periodontitis only in a homozygous model. In fact, CATT7/7 had a greater strength of association and increased odds with respect to CATT6/6 (OR $=4.39,95 \% \mathrm{CI}=1.09-22.28$ and $\mathrm{p}=0.03$ vs $\mathrm{OR}=6.65,95 \% \mathrm{CI}=1.29-42.49$ and $\mathrm{p}=0.02$ ). In the case of the $-173 \mathrm{C} / \mathrm{C}$ genotype, an association was
Table 3. Analysis of the association of MIF alleles and genotypes with the risk of exacerbation of periapical periodontitis

\begin{tabular}{|c|c|c|}
\hline MIF polymorphisms & OR $(95 \% \mathrm{Cl})$ & $p$-value \\
\hline \multicolumn{3}{|c|}{ MIF alleles } \\
\hline \multicolumn{3}{|c|}{$-784 \mathrm{CATT}_{5-8}$} \\
\hline $\mathrm{CATT}_{5}$ & 1 & - \\
\hline $\mathrm{CATT}_{6}$ & $2.8(1.44-5.62)$ & 0.002 \\
\hline $\mathrm{CATT}_{7}$ & $4.13(1.82-9.63)$ & $<0.001$ \\
\hline \multicolumn{3}{|c|}{$-173 \mathrm{G} / \mathrm{C}$} \\
\hline G & 1 & - \\
\hline C & $0.81(0.52-1.28)$ & 0.18 \\
\hline \multicolumn{3}{|c|}{ MIF genotypes } \\
\hline \multicolumn{3}{|c|}{-784 CATT $_{5-8}$} \\
\hline $5 / 5$ & 1 & - \\
\hline $5 / 6$ & $1.32(28.00-7.48)$ & 0.74 \\
\hline $5 / 7$ & $1.91(0.16-20.30)$ & 0.58 \\
\hline $5 / 5$ & 1 & - \\
\hline $6 / 6$ & $4.39(1.09-22.28)$ & 0.03 \\
\hline $6 / 7$ & $3.11(1.63-6.10)$ & $<0.001$ \\
\hline $7 / 7$ & $6.65(1.29-42.49)$ & 0.02 \\
\hline \multicolumn{3}{|c|}{$-173 G / C$} \\
\hline GG co-dominant & 1 & - \\
\hline GC & $1.18(0.54-2.60)$ & 0.67 \\
\hline $\mathrm{CC}$ & $4.1(1.02-20.84)$ & 0.045 \\
\hline GG dominant & 1 & - \\
\hline $\mathrm{GC}+\mathrm{CC}$ & $1.36(0.64-2.91)$ & 0.42 \\
\hline GG+GC recessive & 1 & \\
\hline CC & $3.9(1.064-18.50)$ & 0.019 \\
\hline
\end{tabular}

OR - odds ratio.

observed in a homozygous model $(\mathrm{OR}=4.1 ; 95 \% \mathrm{CI}=1.02-$ $20.84 ; \mathrm{p}=0.045)$ as well as a recessive model $(\mathrm{OR}=3.9$; 95\% CI = 1.064-18.500; $\mathrm{p}=0.019$ ).

An analysis of haplotypes was conducted considering the $-794 \mathrm{CATT}_{5} /-173 \mathrm{G}$ combination as a reference (Table 4).

Table 4. Haplotype frequencies of the -784 CATT $_{5-8}$ and -173G/C MIF polymorphisms and the risk of exacerbation of periapical periodontitis

\begin{tabular}{|l|c|c|c|c|}
\hline Haplotype & $\begin{array}{c}\text { Acute } \\
\text { cases }\end{array}$ & $\begin{array}{c}\text { Chronic } \\
\text { cases }\end{array}$ & OR (95\% Cl) & p-value \\
\hline $\mathrm{CATT}_{5} / \mathrm{G}$ & 10 & 27 & 1 & - \\
\hline $\mathrm{CATT}_{6} / \mathrm{G}$ & 42 & 43 & $\begin{array}{c}1.6 \\
(0.67-4.16)\end{array}$ & 0.13 \\
\hline $\mathrm{CATT}_{7} / \mathrm{G}$ & 18 & 12 & $\begin{array}{c}2.15 \\
(0.85-7.58)\end{array}$ & 0.046 \\
\hline $\mathrm{CATT}_{5} / \mathrm{C}$ & 7 & 12 & $\begin{array}{c}0.99 \\
(0.28-3.42)\end{array}$ & 0.49 \\
\hline $\mathrm{CATT}_{6} / \mathrm{C}$ & 30 & 20 & $\begin{array}{c}2.51 \\
(0.96-6.83)\end{array}$ & 0.03 \\
\hline $\mathrm{CATT}_{7} / \mathrm{C}$ & 13 & 6 & $\begin{array}{c}3.57 \\
(1.038-13.3)\end{array}$ & 0.021 \\
\hline Total $^{2}$ & 120 & 120 & - & - \\
\hline
\end{tabular}


In our results, the $\mathrm{CATT}_{7} / \mathrm{G}$ and $\mathrm{CATT}_{6} / \mathrm{C}$ haplotypes had statistically significant associations with exacerbations of periodontitis $(\mathrm{OR}=2.15,95 \% \mathrm{CI}=0.85-7.58$ and $\mathrm{p}=0.046$ vs $\mathrm{OR}=2.51,95 \% \mathrm{CI}=0.96-6.83$ and $\mathrm{p}=0.03$, respectively). However, the OR for the $\mathrm{CATT}_{7} / \mathrm{C}$ haplotype was greater than the other 2 combinations, taking into consideration that both MIF alleles were associated with a higher risk of inflammation $(\mathrm{OR}=3.57$; 95\% CI $=1.038-$ 13.300; $\mathrm{p}=0.021$ ).

\section{Discussion}

Both MIF -794 CATT $_{5-8}$ and -173G $>$ C polymorphisms have been related to the risk of increasing the severity of the inflammatory response. ${ }^{12,15,18}$ Consequently, we studied both variants as genetic risk factors for exacerbation of inflammation in patients with apical periodontitis. When patients with acute apical periodontitis and chronic apical periodontitis were compared, no correlations were observed in terms of age, sex or BMI in either study group; therefore, possible effects of age, sex or obesity on the exacerbation of periodontitis were ruled out (Table 1). The most frequent allele was $\mathrm{CATT}_{6}(57 \%)$, while the $\mathrm{CATT}_{8}$ allele was not detected, which is consistent with previous reports carried out in the Mexican population. ${ }^{19,20}$ Regarding $M I F-173 \mathrm{G}>\mathrm{C}$ polymorphism, a frequency of $37.5 \%$ for risk allele $C$ was found. This was slightly higher than previously reported for the Mexican population, in which a value around 30\% has been observed; however, those studies were carried out in other geographical regions of Mexico. ${ }^{21-23}$ The -794 CATT alleles showed a significant difference in distribution between the 2 groups, in contrast with the $-173 G>C$ allele, which did not show a different proportion between the acute and chronic groups (Table 2).

The genetic risk of exacerbated apical periodontitis is analyzed in Table 3, noting that $\mathrm{CATT}_{6}$ and $\mathrm{CATT}_{7}$ carriers have almost 3 or 4 times higher potential risk of developing an episode of acute apical periodontitis than $\mathrm{CATT}_{5}$ carriers do; however, either a homozygous condition or CATT6/7 combination seems to be necessary for an acute episode. Indeed, the homozygous carriers of $\mathrm{CATT}_{7}$ showed the highest risk of exacerbation, with an OR value of 6.6 (95\% CI = 1.29-42.49; $\mathrm{p}=0.02)$. In fact, the CATT6/7 genotype has been considered a vulnerability factor for other health risks in the Mexican population, such as acute coronary syndrome and rheumatoid arthritis..$^{19,20}$

On the other hand, risk allele $C$ for the MIF-173 polymorphism was only associated with acute apical periodontitis in a homozygous condition $(\mathrm{OR}=4.1 ; 95 \% \mathrm{CI}=1.02-20.84$; $\mathrm{p}=0.045$ ), but has also been observed in a recessive model where GG+GC genotypes were used as references $(\mathrm{OR}=3.9$; $95 \%$ CI $=1.064-18.500 ; \mathrm{p}=0.019)$. Very recently, several studies have reported that the $\mathrm{C}$ allele in the $M I F-173$ position represents a genetic risk factor associated with diverse disorders or diseases, such as osteoporosis ${ }^{24}$; pulmonary arterial hypertension in patients with systemic sclerosis $^{25}$; tuberculosis ${ }^{26}$; fibrosis in biliary atresia patients ${ }^{27}$; breast cancer, especially among older patients ${ }^{28}$; childhood asthma ${ }^{29}$; and autoimmune hepatitis with acute symptomatic presentation. ${ }^{30}$ However, differences in allele frequency among racial groups is a factor to be considered when interpreting the results. In the present study, none of these diseases was reported by carriers of the $-173 \mathrm{C}$ allele.

When a haplotype analysis was performed considering all the allele combinations between -794 CATT and -193 G>C MIF polymorphisms (Table 4), the association of $\mathrm{CATT}_{7}$ and $-173 \mathrm{C}$ showed the greatest risk of exacerbating periodontitis, which concurs with other studies where the $\mathrm{CATT}_{7} /-173 \mathrm{C}$ haplotype has been shown to be related to an increased inflammatory process. ${ }^{12,19}$ Particularly, the $\mathrm{CATT}_{7} /-173 \mathrm{C}$ combination has been considered a risk factor for death in carriers with severe sepsis, ${ }^{31}$ as well as a risk factor for inflammatory polyarthritis. ${ }^{32}$

Since MIF -794 $\mathrm{CATT}_{7}$ and $-173 \mathrm{C}$ polymorphisms can modify the gene expression and therefore the production of MIF, carriers of this allele combination would have higher levels of circulating MIF, with a consequent predisposition to an increased response to inflammatory processes $^{13,31,33}$; however, plasma MIF levels were not determined in this study. More investigations into the role of MIF in the development and severity of apical periodontitis as well as the genetic predisposition to exacerbation are needed.

\section{Conclusions}

Although several studies have shown that MIF plays a role in the pathogenesis of apical periodontitis as a promoter of other pro-inflammatory molecules, ${ }^{7,9,10,34}$ MIF polymorphisms have only been studied in systemic types of inflammatory disorders, such as sclerosis, tuberculosis, fibrosis, and asthma. ${ }^{25-27,29}$ Very few studies have looked at MIF polymorphisms in diseases of the oral cavity. ${ }^{35}$ There are few reports in the literature about polymorphisms in pro-inflammatory cytokine genes related to apical periodontitis. ${ }^{36-38}$ This study is the first report where a positive association has been found between acute stages in patients with apical periodontitis and -794 $\mathrm{CATT}_{7}$ and $M I F-173 C$ polymorphisms.

\section{References}

1. Nair PN. Apical periodontitis: A dynamic encounter between root canal infection and host response. Periodontol 2000. 1997;13:121-148.

2. Kirkevang LL, Vaeth $M$, Hörsted-Bindslev $P$, Wenzel A. Longitudinal study of periapical and endodontic status in a Danish population. Int Endod J. 2006;39(2):100-107.

3. Jiménez-Pinzón A, Segura-Egea JJ,Poyato-Ferrera M, Velasco-OrtegaE, Ríos-Santos JV. Prevalence of apical periodontitis and frequency of root-filled teeth in an adult Spanish population. Int Endod J. 2004; 37(3):167-173. 
4. Hussein FE, Liew AK, Ramlee RA, Abdullah D, Chong BS. Factors associated with apical periodontitis: A multilevel analysis. J Endod. 2016; 42(10):1441-1445.

5. Abbott PV. Classification, diagnosis and clinical manifestations of apical periodontitis. Endod Topics. 2014;8(1):36-54.

6. Jakovljevic A, Knezevic A, Karalic D. Pro-inflammatory cytokine levels in human apical periodontitis: Correlation with clinical and histological findings. Aust Endod J. 2015;41(2):72-77.

7. Calandra T, Roger T. Macrophage migration inhibitory factor: A regulator of innate immunity. Nat Rev Immunol. 2003;3(10):791-800.

8. Donn RP, Ray DW. Macrophage migration inhibitory factor: Molecular, cellular and genetic aspects of a key neuroendocrine molecule. J Endocrinol. 2004;182(1):1-9.

9. Onodera S, Nishihira J, Iwabuchi K, et al. Macrophage migration inhibitory factor up-regulates matrix metalloproteinase- 9 and -13 in rat osteoblasts: Relevance to intracellular signaling pathways. J Biol Chem. 2010;277(10):7865-7874. doi:10.1074/jbc.M106020200

10. Toh M, Aeberli D, Lacey D, et al. Regulation of IL-1 and TNF receptor expression and function by endogenous macrophage migration inhibitory factor. J Immunol. 2006;177(7):4818-4825.

11. Grieb G, Merk M, Bernhagen J, Bucala R. Macrophage migration inhibitory factor (MIF): A promising biomarker. Drug News Perspect. 2010;23(4):257-264

12. Renner $P$, Roger T, Calandra T. Macrophage migration inhibitory factor: Gene polymorphisms and susceptibility to inflammatory diseases. Clin Infect Dis. 2005;41(Suppl 7):S513-519.

13. Baugh JA, Chitnis S, Donnelly SC. A functional promoter polymorphism in the macrophage migration inhibitory factor (MIF) gene associated with disease severity in rheumatoid arthritis. Genes Immun. 2002;3(3):170-176.

14. Bucala R. MIF alleles and the regulation of the host response. In: Bucala R, ed. The MIF Handbook. Hackensack, NJ: World Scientific Publishing Company; 2012.

15. Bucala R. MIF alleles, and prospects for therapeutic intervention in autoimmunity. J Clin Immunol. 2013;33(Suppl 1):S72-78.

16. García-Sepulveda CA, Carrillo-Acuña E, Guerra-Palomares SE, BarrigaMoreno M. Maxiprep genomic DNA extractions for molecular epidemiology studies and biorepositories. Mol Biol Rep. 2010;37(4): 1883-1890.

17. Matia-García I, Salgado-Goytia L, Muñoz-Valle JF, et al. Macrophage migration inhibitory factor promoter polymorphisms (-794 CATT 5-8 and -173 G>C): Relationship with mRNA expression and soluble MIF levels in young obese subjects. Dis Markers. 2015;461208. doi:10.1155/2015/461208

18. Falvey JD, Bentley RW, Merriman TR, et al. Macrophage migration inhibitory factor gene polymorphisms in inflammatory bowel disease: An association study in New Zealand Caucasians and metaanalysis. World J Gastroenterol. 2013;19(39):6656-6664.

19. Llamas-Covarrubias MA, Valle $Y$, Bucala $R$, et al. Macrophage migration inhibitory factor (MIF): Genetic evidence for participation in early onset and early stage rheumatoid arthritis. Cytokine. 2013;61(3): 759-765.

20. Valdés-Alvarado E, Muñoz-Valle JF, Valle Y, et al. Association between the -794 (CATT)5-8 MIF gene polymorphism and susceptibility to acute coronary syndrome in a Western Mexican population. J Immunol Res. 2014;2014:704854. doi:10.1155/2014/704854

21. De la Cruz-Mosso U, Bucala R, Palafox-Sánchez CA, et al. Macrophage migration inhibitory factor: Association of -794 CATT5-8 and -173 G>C polymorphisms with TNF-a in systemic lupus erythematosus. Hum Immunol. 2014;75(5):433-439. doi:10.1016/j.humimm.2014.02.014
22. Morales-Zambrano R, Bautista-Herrera LA, De la Cruz-Mosso U, et al. Macrophage migration inhibitory factor (MIF) promoter polymorphisms (-794 CATT5-8 and -173 G>C): association with MIF and TNFa in psoriatic arthritis. Int J Clin Exp Med. 2014;7(9):2605-2614.

23. Martínez-Guzman MA, Alvarado-Navarro A, Pereira-Suarez AL, Muñoz-Valle JF, Fafutis-Morris M. Association between STR -794 CATT5-8 and SNP-173 G/C polymorphisms in the MIF gene and lepromatous leprosy in Mestizo patients of western Mexico. Hum Immunol. 2016;77(10):985-989. doi:10.1016/j.humimm.2016.07.006

24. Ozsoy AZ, Karakus N, Tural S, et al. Influence of the MIF polymorphism $-173 \mathrm{G}>\mathrm{C}$ on Turkish postmenopausal women with osteoporosis. Z Rheumatol. 2017;77(7):629-632. doi:10.1007/s00393-017-0382-5

25. Bossini-Castillo L, Campillo-Davó D, López-Isac E, et al; Spanish Scleroderma Group. An MIF promoter polymorphism is associated with susceptibility to pulmonary arterial hypertension in diffuse cutaneous systemic sclerosis. J Rheumatol. 2017;44(10):1453-1457.

26. Naderi $M$, Hashemi $M$, Ansari $H$. Macrophage migration inhibitory factor $-173 \mathrm{G}>\mathrm{C}$ polymorphism and risk of tuberculosis: A meta-analysis. EXCLI J. 2017;16:313-320. doi:10.17179/excli2016-662

27. Sadek KH, Ezzat S, Abdel-Aziz SA, Alaraby H, Mosbeh A, AbdelRahman MH. Macrophage migration inhibitory factor (MIF) gene promotor polymorphism is associated with increased fibrosis in biliary atresia patients, but not with disease susceptibility. Ann Hum Genet. 2017;81(5):177-183.

28. Lin S, Wang M, Liu X, et al. Association of genetic polymorphisms in MIF with breast cancer risk in Chinese women. Clin Exp Med. 2017; 17(3):395-301.

29. El-Adly TZ, Kamal S, Selim H, Botros S. Association of macrophage migration inhibitory factor promoter polymorphism -173G/C with susceptibility to childhood asthma. Cent Eur J Immunol. 2016;41(3): 268-272.

30. Assis DN, Takahashi H, Leng L, Zeniya M, Boyer JL, Bucala R. A macrophage migration inhibitory factor polymorphism is associated with autoimmune hepatitis severity in US and Japanese patients. Dig Dis Sci. 2016;61(12):3506-3512.

31. Lehmann LE, Book M, Hartmann W, et al. A MIF haplotype is associated with the outcome of patients with severe sepsis: A case control study. J Trans/ Med. 2009;7:100.

32. Barton A, Lamb R, Symmons D, et al. Macrophage migration inhibitory factor (MIF) gene polymorphism is associated with susceptibility to but not severity of inflammatory polyarthritis. Genes Immun. 2003;4(7):487-491.

33. Qian L, Wang XY, Thapa S, et al. Macrophage migration inhibitory factor promoter polymorphisms (-794 CATT5-8): Relationship with soluble MIF levels in coronary atherosclerotic disease subjects. BMC Cardiovasc Disord. 2017;17(1):144.

34. Liu $L$, Peng $B$. The expression of macrophage migration inhibitory factor is correlated with receptor activator of nuclear factor kappa $b$ ligand in induced rat apical lesions. J Endod. 2013;39(8):984-989.

35. Heidari Z, Mahmoudzadeh-Sagheb H, Hashemi M, Ansarimoghaddam S, Moudi B, Sheibak N. Association of macrophage migration inhibitory factor gene polymorphisms with chronic periodontitis in a South Eastern Iranian population. Dent Res J (Isfahan). 2017;14(6): 395-402.

36. de Sá AR, Moreira PR, Xavier GM, et al. Association of CD14, IL1B, IL6, IL10 and TNFa functional gene polymorphisms with symptomatic dental abscesses. Int Endod J. 2007;40(7):563-572.

37. Amaya MP, Criado L, Blanco B, et al. Polymorphisms of pro-inflammatory cytokine genes and the risk for acute suppurative or chronic nonsuppurative apical periodontitis in a Colombian population. Int Endod J. 2013;46(1):71-78.

38. Aminoshariae A, Kulild JC. Association of functional gene polymorphism with apical periodontitis. J Endod. 2015;41(7):999-1007. 